\title{
Alfabetização Científica: possibilidades didático- pedagógicas da revista Ciência Hoje das Crianças Online
}

\author{
Maria do Rocio Fontoura Teixeira ${ }^{1}$ \\ Juliana Carvalho Pereira ${ }^{2}$ \\ Ketlen Stueber ${ }^{3}$
}

\begin{abstract}
RESUMO
Analisa trinta e cinco textos da revista Ciência Hoje para as Crianças Online, considerando-a como fonte de informação na perspectiva didáticopedagógicas para a mediação da Alfabetização Científica. A questão principal do estudo foi: Como a revista Ciência Hoje das Crianças Online pode viabilizar a Alfabetização Científica no ensinar e aprender ciência? A abordagem metodológica foi de natureza qualitativa e fundamentou-se na pesquisa bibliográfica e na análise de conteúdo. Identificaram-se os autores e as instituições que contribuíram na produção dos textos e a que público se destinavam. Elencaram-se os facilitadores de Alfabetização Científica, níveis de interdisciplinaridade e as possíveis aplicabilidades didático-pedagógicas. Conclui-se que as matérias analisadas possuem viabilidade pedagógica, fomentam debates e reflexões a partir do conhecimento científico. Evidencia-se a atuação da revista no Ensino de Ciências e indica o quão necessário são as investigações de temas no viés científico que possam fomentar práticas inovadoras na perspectiva do ensino interdisciplinar.
\end{abstract}

PALAVRAS-CHAVE: Ensino de Ciências. Alfabetização Científica. Ciência Hoje das Crianças.

Scientific Literacy: didactic-pedagogical possibilities of the Science magazine Ciência Hoje das Crianças online

\footnotetext{
${ }^{1}$ Doutora em Educação em Ciências. Coordenadora do Programa de Pós-Graduação em Educação em Ciências: Química da Vida e Saúde - UFRGS. Professora Adjunta do Departamento de Ciências da Informação, FABICO UFRGS. Porto Alegre, RS. E-mail: maria.teixeira@ufrgs.br.

2 Mestre em Educação em Ciências. Doutoranda do Programa de Pós-Graduação em Educação em Ciências: Química da Vida e Saúde - UFRGS, Porto Alegre, RS. E-mail: juliana.pereira@ufrgs.br

${ }^{3}$ Mestre em Comunicação e Informação. Doutoranda do Programa de Pós-Graduação em Educação em Ciências: Química da Vida e Saúde - UFRGS, Porto Alegre, RS. E-mail: ketistueber@hotmail.com
} 


\begin{abstract}
It analyses thirty-five texts of the magazine Ciência Hoje das Crianças Online considering them source of information with didactic-pedagogical perspective for the mediation of Scientific Literacy. The main question of the study was: How can the online magazine Ciência Hoje das Crianças Online enable scientific literacy in teaching and learning science? The methodological approach was qualitative in nature and was based on bibliographic research and content analysis. The authors and institutions that contributed to the production of the texts and the intended audience were identified. The facilitators of Scientific Literacy, levels of interdisciplinary and the possible didactic-pedagogical applicability were listed. It is concluded that the analyses materials have pedagogical feasibility, foment debates and reflections from the scientific knowledge. The journal's performance in Science Teaching is shown and indicates how necessary are the investigations of topics in the scientific bias that can foster innovative practices in the perspective of interdisciplinary teaching.
\end{abstract}

KEYWORDS: Science Teaching. Scientific Literacy. Ciência Hoje das Crianças

$$
* * *
$$

\title{
Introdução
}

O campo do Ensino é fértil para o uso das diversas possibilidades de ensinar e de aprender, permeadas de recursos advindos dos avanços tecnológicos e científicos. O acesso e o uso de fontes de informação estão inseridos neste contexto. Do ponto de vista cognitivo, estes recursos podem contribuir para a reformulação de conceitos significativos e novas abordagens pedagógicas, de modo a utilizar a internet como ferramenta, para a leitura, para a resolução de problemas e, ainda, na elaboração de projetos (ROCHA, MASSARANI, 2016).

Diante dessas questões que exigem habilidades para distinguir de que modo a informação online contribui para o aprendizado, buscamos responder nas páginas a seguir a questão norteadora deste estudo: Como a revista 
Ciência Hoje das Crianças (CHC) Online pode viabilizar a Alfabetização Científica no ensinar e no aprender ciências?

Cabe considerar que o acesso ao conhecimento necessita estar à disposição da comunidade escolar para alcançar determinados objetivos. $\mathrm{O}$ ato de aprender consiste em construir significações entre os pressupostos teóricos das diversas áreas do saber com o entorno e a realidade social dos estudantes. O “ensinar e aprender exigem hoje muito mais flexibilidade espaço-temporal, pessoal e de grupo, menos conteúdos fixos e processos mais abertos de pesquisa e de comunicação" (MORAN, 2009, p. 29). A oferta de conteúdo é a garantia de descobrir se algo está adequado às necessidades do indivíduo e permitir transformá-la em conhecimento. $\mathrm{O}$ desafio da quantidade excessiva de conteúdos disponibilizado pela internet também podem provocar inúmeras inconsistências no ensinar e no aprender se o professor estiver preparado apenas numa pedagogia referenciada em acúmulo de informações, visto que o “[...] ensinar não é transferir conhecimento, mas criar as possibilidades para a sua própria produção ou a sua construção" (FREIRE, 1996, p. 25). Sendo assim, é importante a seleção de recursos e dos dispositivos alternativos que contribuam para o processo de ensino-aprendizagem e que possam consolidar uma formação autônoma e crítica aos estudantes.

A argumentação incide no professor e na busca de situações que oriente os alunos no processo de interação, incentivo do trabalho em grupo, na pesquisa de novas fontes de informações e, consequentemente, na produção de novos conhecimentos. Essas ações proporcionam "[...] oportunidades a fim de que valores, crenças e questões sobre cidadania possam ser trabalhados, preparando e desenvolvendo as competências necessárias para que esse aprendiz possa viver e usufruir a sociedade do conhecimento" (VALENTE, 2017, p. 42). Nessa perspectiva, a revista CHC Online apresenta aspectos relevantes de estudo, principalmente se considerada a partir dos pressupostos e indicadores da Alfabetização Científica (AC). 
Assim, a possibilidade didático-pedagógica deste estudo parte do uso da revista $\mathrm{CHC}$ Online e para fundamentar esta afirmativa, realizou-se uma análise aprofundada nos textos da revista elencados em sete categorias (astronomia, bichos, física, meio ambiente, plantas, química e saúde) que podem ser abordadas no Ensino de Ciências. Buscou-se saber a origem dos textos (autores e instituições) e se o conteúdo contempla o público infantil e os estudantes dos anos iniciais. Na seção Interdisciplinaridade nos artigos da CHC Online e as aplicabilidades pedagógicas, identificamos quais os temas foram mais abordados nas 35 matérias de acordo com suas categorias e como estas categorias se interligavam com diferentes campos do saber para formar uma rede de conhecimentos interdisciplinares.

Verificou-se também nas matérias analisadas a aproximação com diversos conteúdos escolares referentes ao Ensino de Ciências da Natureza nos anos iniciais. Este fator corrobora com as possibilidades didáticopedagógicas, no entanto, não cabe a este estudo sugerir métodos e atividades específicas, pois, preferiu-se respeitar as singularidades, recursos e abordagens dos professores em suas práticas de ensino-aprendizagem.

\section{Alfabetização Científica (AC): possiveis indicadores para promover a aprendizagem}

A literatura em geral vem mostrando o quanto o conhecimento científico é relevante na sociedade que procura acompanhar a inovação tecnológica e o avanço social. Os estudantes necessitam alcançar uma formação crítica, para compreender o mundo e a suas transformações, através do desenvolvimento das competências que envolvem principalmente o Ensino de Ciências e as relações necessárias na construção do saber científico (TENREIRO-VIEIRA; VIEIRA, 2011).

Encontra-se entre os pesquisadores (DELIZOICOV; ANGOTTI; PERNAMBUCO, 2009; HOLBROOK; RANNIKMAE, 2009; NORRIS; PHILLIPS, 2003; SASSERON; CARVALHO, 2008; dentre outros) a existência de uma diversidade de conceitos para definir o que efetivamente 
seja a AC em nosso cenário atual. São estas articulações que perpassam desde a explosão de ideias e argumentos, a estudos empíricos ou ainda a leituras críticas sobre o Ensino de Ciências.

Para Chassot (2018, p. 84), estar alfabetizado cientificamente significa possuir "o conjunto de conhecimentos que facilitariam aos homens e mulheres fazer uma leitura do mundo onde vivem". De modo a fornecer subsídios para que os estudantes possam, por exemplo, posicionar-se diante de questões ambientais, como desmatamento, poluição, o destino do lixo, aquecimento global, dentre outros temas de relevância social e científica.

Sasseron e Carvalho (2008) apresentam três pontos principais a serem considerados no indivíduo alfabetizado cientificamente. São eles: a) compreensão básica de conceitos científicos; b) a compreensão da natureza das Ciências e dos fatores éticos e políticos que circundam sua prática; e c) o entendimento das relações existentes entre ciência, tecnologia, sociedade e meio ambiente. Para essas pesquisadoras, os eixos estruturantes da AC, "nos servem de apoio na idealização, planejamento e análise de propostas de ensino que almejam a AC" (SASSERON; CARVALHO, 2008, p. 335).

É fundamental apresentar alguns dos indicadores da Alfabetização Científica, construídos pelos pesquisadores da área. Para Sasseron e Carvalho (2008, p. 337), nos processos de "Alfabetização Científica, é importante que os alunos travem contato e conhecimento de habilidades associada ao trabalho do cientista." As competências sucedidas das Ciências e do fazer científico relacionado aos dados coletados, como a seriação, organização e classificação de uma informação, são indicadores fundamentais quando a investigação envolve as muitas variáveis de um fenômeno. Ou ainda, na dimensão da estrutura do pensamento como o raciocínio lógico e proporcional. E, por fim, indicadores relacionados a interpretar uma situação investigada. São eles: levantamento de hipóteses, teste de hipóteses, justificativa, previsão e explicação (SASSERON; CARVALHO, 2008). As autoras ressaltam que alguns indicadores de AC podem ser encontrados em aulas de Ciências a partir da observação e de 
análise de situações em sala de aula, além do modo como o estudante pode reagir quando se depara com algum problema durante o processo de investigação.

Nos estudos de Holbrook e Rannikmae (2009), a AC, no viés da educação científica, compreende campos do conhecimento, como a natureza da Ciência e o desenvolvimento pessoal e social. Através do domínio dessas competências cognitivas em ciências, os estudantes podem compreender e aplicar conceitos e fenômenos científicos. Para esses autores, os domínios a serem ampliados aos estudantes para possibilitar as condições adequadas da atividade científica e as questões socio científicas relevantes perpassam pelas práxis da AC.

Para alcançar a compreensão das atividades investigativas através da resolução de problemas científicos, os estudantes devem ter participação ativa em etapas como a observação, a exposição do problema, a formulação de testes e das hipóteses, assim como defender e discutir possibilidades para as evidências observadas. As habilidades priorizadas vão desde a comunicação oral, a linguagem textual e simbólica, dentre outras.

De acordo com Pizarro e Lopes Junior (2015), os indicadores da AC possibilitam visualizar os avanços dos estudantes nas atividades desenvolvidas pelo professor, colocando o estudante como o sujeito de sua própria aprendizagem em qualquer etapa ou nível de escolarização. A proposta de definição de indicadores numa perspectiva social desde os anos iniciais do ensino fundamental apresenta-se no quadro 1.

As pesquisas, como a citada no quadro 1, indicam a gama de possibilidade da AC e esta pode ser promovida como um objetivo de ensino e aprendizagem em ciências numa abordagem interdisciplinar, como contributo de aulas no espaço formal, sendo mais atrativa e significativa ao estudante. No entanto, os estudos vêm indicando o quão pouco compreendida a interdisciplinaridade no meio escolar, embora percebamos esta como uma demanda da sociedade, tal a importância dos estudantes com visões amplas e integrados para a resolução de problemas. Segundo Mozena 
e Ostermann (2014, p. 186) a "[...] organização curricular por disciplinas tradicionais, que gera um acúmulo de informações, mas pouca contribuição para a vida pessoal e profissional [...]", acabam sendo estudadas de forma isolada, limitando a interconexão entre as áreas do conhecimento defendida por Fazenda (2012) e outros.

QUADRO 1 - Indicadores de AC na perspectiva social

\section{Articular ideias e o investigar} quando:

a) estabelecer relações;

b) envolver atividades que necessite de apoio do conhecimento científico;

c) construir explicações com base na sua pesquisa e compartilhar com colegas e professores.

Escrever em ciências e problematizar quando:

a) produzir textos com

posicionamento crítico nos variados temas em ciências;

b) articular sua produção, os seus conhecimentos com os dados das fontes de estudos;

c) questionar e buscar as informações em diferentes fontes sobre os usos e os impactos da ciência.

\section{Argumentar e ler em ciências} quando:

a) defender seu argumento, apoiado em ideias próprias a partir do conhecimento adquirido em debates de sala de aula;

b) relacionar o conhecimento e conceitos científicos a partir de leituras realizadas do gênero científico.

\section{Criar e o atuar quando:}

a) participar de atividades com novas ideias, ter os argumentos, posturas e as soluções para problemáticas que envolvem a ciência e o fazer científico;

b) compreender o que é um agente de mudanças, diante do desafio, em relação a sociedade e o meio ambiente.

Fonte: Adaptado de Pizarro, Lopes Junior (2015)

Nesse contexto, a polissemia do tema e os discursos oficiais ainda parecem estar distantes da sala de aula e da prática dos conhecimentos dos professores. Segundo os resultados da pesquisa de Mozena e Otermann (2014, p. 200), o "objeto em estudo na escola necessita de uma abordagem interdisciplinar para seu entendimento". Isso reforça a importância da discussão e debates da abordagem interdisciplinar em âmbito nacional, para promover avanços significativos no Ensino de Ciências em consonância com iniciativas inovadoras que possam fomentar práticas de sucesso.

\section{A divulgação científica na CHC online: aspectos a considerar para a melhoria do Ensino de Ciências}


O ensino de Ciências deve se apropriar da divulgação científica formal e não formal enquanto instrumento útil de educação. Na pesquisa realizada por Massarani (2007) aponta como exemplo a utilização da revista CHC online. Para Massarani (2007), as crianças têm se mostrado muito mais receptivas para ideias e conteúdos relacionados à Ciência do que os adolescentes e os adultos, isso se deve à intensa curiosidade inerente à infância e necessita ser encarado como uma oportunidade para a divulgação do conhecimento científico.

Muitos materiais para a mediação, principalmente os livros didáticos, são inadequados, seja pela carência de aspectos gráficos, seja pela rigidez de seus conteúdos textuais, impedindo que os leitores criem vínculos e relações significativas entre o entorno em que vivem e a Ciência. Este fenômeno não permite que a atividade científica seja percebida de modo claro, através de suas potencialidades ou limitações.

A revista Ciência Hoje das Crianças surgiu como suplemento da revista Ciência Hoje, criada em 1986 pela Sociedade Brasileira para o Progresso da Ciência (SBPC). Devido ao sucesso entre o público infantil e a singularidade de conteúdo, em 1991, a revista Ciência Hoje das Crianças ganhou autonomia. Em 2001, as publicações passam ser produzidas pelo Instituto Ciência Hoje (ICH), órgão vinculado à SBPC, mas com independência administrativo-financeira (INSTITUTO, 2016).

A revista Ciência Hoje das Crianças foi a primeira do Brasil destinada a divulgar a importância da ciência para o público infantil, a partir de exemplos e situações cotidianas. Desenvolvidos por pesquisadores e cientistas, os textos possuem linguagem clara e acessível, buscam abordar temas relacionados às descobertas sobre o planeta, os biomas e espécies da fauna e da flora brasileira, os animais em risco de extinção, dentre outros temas voltados ao universo da Ciência. Apresenta também discussões sobre pesquisas, experimentos e o futuro do planeta, além de tirar dúvidas sobre as questões científicas que podem surgir a partir dos temas propostos 
(SOBRE..., [2016]). Com base nos conteúdos publicados pela revista impressa e digital da $\mathrm{CHC}$, muitos livros e programas de televisão foram editados e serviços de consultoria foram desenvolvidos. Mais de 60.000 escolas públicas brasileiras receberam a revista impressa em suas bibliotecas (SOBRE..., [2016]), o que denota o quanto este material pode contribuir para a democratização do conhecimento científico voltado para o público infantil e jovem.

O website oficial da CHC surgiu em 2001. A CHC Online disponibiliza sugestões de e-books interativos, jogos, aplicativos, matérias, infográficos e edições da revista (impressa e digital). A revista online passou por transformações de layout em meados de junho de 2018. Não houve perda de conteúdo das matérias, mas as mudanças na interface e na estrutura de alguns tópicos redimensionam as formas de interação e acesso aos materiais analisados. As descrições acerca da coleta de dados conforme apresentados nos procedimentos metodológicos foram desenvolvidas a partir do layout disponível em abril de 2018, anterior às mudanças. As matérias analisadas e selecionadas, conforme as interfaces pesquisadas, estão referenciadas no final do artigo e permanecem acessíveis e online.

Como podemos perceber, as pesquisas apontam que a Ciência Hoje das Crianças apresenta um "importante papel na divulgação científica, a revista tem sido reconhecida como material de qualidade no apoio ao Ensino de Ciências na Educação Básica" (FRAGA, ROSA, 2015, p. 202). Almeida e Giordan (2014) analisaram como as crianças de nove e dez anos de idade, estudantes do $4^{\circ}$ ano do Ensino Fundamental de uma escola pública em Belo Horizonte - MG, apropriaram-se e reproduzem o discurso da revista Ciência Hoje das Crianças a partir de suas características científicas e informativas.

O estudo de Fraga e Rosa (2015) destacou a importância do incentivo à leitura nas aulas de Ciências como forma de apropriação de conhecimentos científicos. O uso desta revista através de interações orais e escritas evidenciaram que as crianças utilizam o conteúdo para expressar seus 
conhecimentos, construir ideias e habilidades, resultando em formas efetivas de retextualização e letramento através da divulgação científica.

\section{Metodologia}

$\mathrm{O}$ estudo foi de natureza qualitativa e fundamentou-se em pesquisa bibliográfica na internet. Gil (2008) afirma que o levantamento bibliográfico busca a investigação, compreensão e descrição das informações que auxiliem compreender os objetos de estudo. Para coleta e análise de dados, aplicou-se a análise de conteúdo (BARDIN, 2009). A análise de conteúdo está dividida em três etapas principais: pré-análise; exploração do material e; tratamento dos resultados e interpretações. Na fase de pré-análise, busca-se selecionar o objeto de estudo e delimitá-lo através de critérios para recorte. Neste estudo, a pré-análise foi aplicada a partir das categorias temáticas propostas na CHC Online coletadas em abril de 2018: astronomia, bichos, física, meio ambiente, plantas, química e saúde. As categorias eleitas estão diretamente associadas com o Ensino de Ciências. Para cada categoria, foram coletadas as cinco matérias mais atuais, gerando um corpus total de 35 matérias.

A exploração do material consiste em administrar técnicas sobre o corpus (BARDIN, 2009). Logo, para cada matéria, foram desenvolvidos quadros com campos a serem preenchidos, visando identificar características do conteúdo conforme apresentadas no quadro 2.

Através do quadro 2 buscou-se registrar a categoria geral das matérias na CHC Online; título; data de publicação; link e data de acesso da coleta e leitura das matérias; atores envolvidos como o perfil dos autores e instituições que produzem o conteúdo; público destinado a partir do perfil escolar e; facilitadores de Alfabetização Científica através de temas propostos em cada matéria, os níveis de interdisciplinaridade e as aplicabilidades didático-pedagógicas. 
QUADRO 2 - Modelo de quadro utilizado para coleta e análise das 35 matérias da revista CHC Online

Categoria principal na CHC:

Subcategorias (se houver):

Título:

Data:

Link: Data de acesso:

Atores

Perfil do autor:

Facilitadores da Alfabetização Científica

Tema(s) geral(is):

Aplicabilidades práticas:

Aplicabilidades teóricas:

Eixos de interdisciplinaridade:

Viabilidade para projetos didático-pedagógicos na escola:

Fonte: Autores, 2018

O tratamento de resultados e interpretações, segundo Bardin (2009), visa apresentar operações estatísticas e também a frequência do uso dos termos, sintetizar os resultados, apresentar inferências e interpretações, com fins teóricos ou pragmáticos. As matérias selecionadas foram lidas e indexadas a partir da inserção de termos representativos ao conteúdo disposto. A análise, disposta nas seções a seguir, ilustram e descrevem os resultados obtidos a partir dos critérios de identificação sobre as os atores envolvidos, as características do conteúdo e os facilitadores de AC, eixos norteadores que contribuem com a demanda levantada na questão inicial da pesquisa.

\section{Autores e instituições da CHC Online identificados}

Os 35 artigos analisados tiveram a colaboração de 27 autores diferentes, alguns assinam em mais de uma matéria. Identificou-se também a presença de autores 'anônimos', que receberam a designação de 'personagem fictício', devido à existência de matérias assinadas em nome dos personagens infantis da revista: Zíper e Rex. Por trás desses personagens, não é possível identificar a quantidade e o perfil real desses autores, logo optou-se por considerar esse corpo editorial como um único agente. Portanto, as 35 matérias são produzidas por 26 autores considerados reais, sendo 12 do sexo feminino, 14 do sexo masculino. O 
perfil dos autores envolvidos está implícito nas características dos conteúdos produzidos e nos aspectos de interdisciplinaridade.

Das 12 autoras, quatro são formadas em Biologia, quatro não tiveram a formação identificada e cada uma das demais são identificadas como editora, epidemiologista, farmacêutica e jornalista. Dentre os 14 autores, quatro são formados em Biologia, dois em Educação Física e quatro não tiveram a formação identificada. Os outros cinco autores, derivam cada um da área da Física, Geofísica, Medicina, ou áreas afins, Psiquiatria e Química. A formação dos autores e autoras, advindos de diferentes perspectivas e campos do saber é rica e variada.

Através das matérias, foram identificadas 14 instituições colaboradoras, a maioria universidades públicas. No entanto, também há contribuições da equipe editorial da revista CHC Online, de institutos, museus e programas/projetos descritos na figura 1.

FIGURA 1- Instituições Colaboradoras da CHC Online

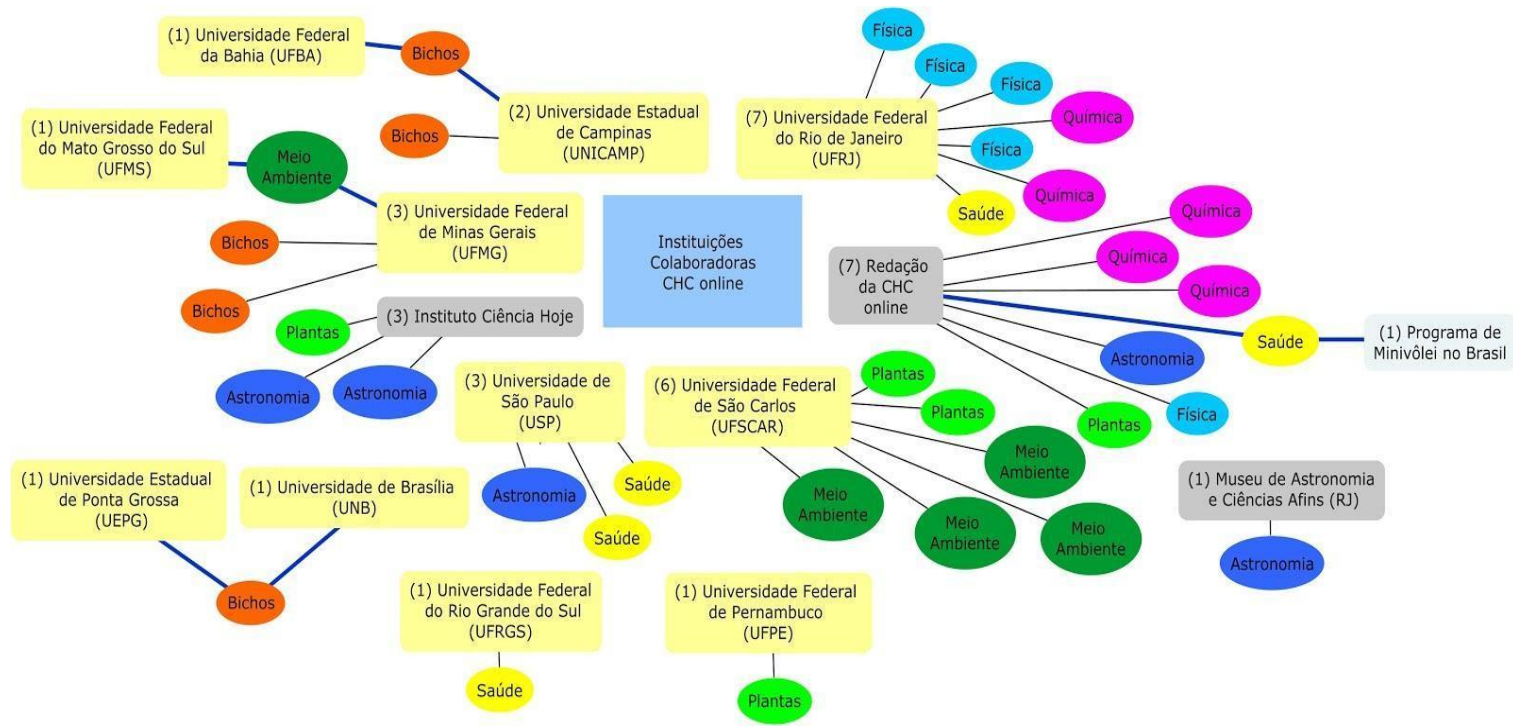

Legenda: Análise das cinco matérias mais recentes coletadas em Abril de 2018, nas categorias astronomia, bichos, física, meio ambiente, plantas, química e saúde. Entre parênteses, encontra-se o número de matérias publicadas ao lado de cada instituição colaboradora. As linhas em destaque (que conectam as instituições com as categorias gerais) revelam produções publicadas em parceria entre instituições.

Fonte: Autores, 2018. 
Dentre as universidades mais produtivas, estão a Universidade Federal do Rio de Janeiro (UFRJ), com sete matérias, sendo quatro produzidas pelo corpo docente do seu Colégio de Aplicação para a categoria Física, duas matérias na categoria Química e uma na Saúde. A Universidade Federal de São Carlos (UFSCAR), com seis publicações, sendo quatro da categoria Meio Ambiente e dois da categoria Plantas. A Universidade Federal de Minas Gerais (UFMG) contribuiu com três matérias, sendo duas na categoria Bichos e uma na categoria Meio Ambiente sendo esta elaborada em parceria com a Universidade Federal do Mato Grosso do Sul(UFMT); A Universidade de São Paulo (USP) contribuiu com três matérias, duas pertencentes à categoria Astronomia e uma na categoria Saúde. A Universidade Estadual de Campinas (UNICAMP) contribuiu com duas matérias, ambas na categoria Bichos, sendo uma publicada em parceria com a Universidade Federal da Bahia (UFBA).

As demais instituições universitárias produziram uma matéria nas seguintes categorias: UFBA, em parceria com a UNICAMP produziram na categoria Bichos. A Universidade Estadual de Ponta Grossa (UEPG) e a Universidade de Brasília (UNB) também produziram para a categoria Bichos. A Universidade Federal do Mato Grosso do Sul (UFMS) produziu em parceria com a Universidade Federal de Minas Gerais (UFMG) para a categoria Meio Ambiente. A Universidade Federal de Pernambuco (UFPE) publicou na categoria Plantas. A Universidade Federal do Rio Grande do Sul (UFRGS) produziu na categoria Saúde.

A redação formada pela equipe editorial da revista CHC Online produziu sete matérias, sendo três delas na categoria Química, e, respectivamente, uma matéria na categoria Plantas, Astronomia, Física e Saúde, sendo esta em parceria com o Instituto Minivôlei Brasil. O Instituto Ciência Hoje contribui com a publicação de três matérias, sendo duas na categoria Plantas e uma na categoria Astronomia. O Museu de Astronomia e Ciências Afins do Rio de Janeiro produziu uma matéria na categoria Astronomia. E o Programa Minivôlei Brasil, como já citado acima, publicou 
uma matéria na categoria Saúde em parceria com a redação da Ciência Hoje das Crianças.

A quem se destinam as matérias? Logo, voltada para o público infantil e juvenil, a CHC Online possui layout amigável e atraente, a linguagem é acessível e fluida. Esses fatores possibilitam que a informação científica seja disseminada de forma lúdica. Em âmbito escolar, pode ser um atrativo para o Ensino de Ciências, como por exemplo até o quinto ano do Ensino Fundamental. No entanto, é preciso considerar também que matérias desse tipo podem ser disseminadas entre leitores de diferentes idades e níveis de alfabetismo, a partir de seus interesses pessoais ou dos temas desenvolvidos no espaço escolar.

\section{Interdisciplinaridade e as possíveis aplicabilidades pedagógicas}

Nesta etapa da pesquisa, os textos foram lidos e analisados, a partir dos conteúdos e especificidades de cada artigo, com o intuito de elencar termos representativos. Esse processo deu-se de modo livre pelas pesquisadoras, considerando as etapas de análise de conteúdo (BARDIN, 2009) e as possíveis mediações que podem ser realizadas em sala de aula para alcançar possíveis práticas da AC, considerando englobar os conteúdos e os métodos da Ciências da Natureza para os anos iniciais do Ensino Fundamental I.

Do universo de 35 artigos, foi possível percebermos a variabilidade e a riqueza de assuntos identificados e apontam o potencial dos textos enquanto facilitadores da prática da $\mathrm{AC}$ em ambientes de aprendizagem. Em cada uma das categorias analisadas na CHC Online nesta pesquisa, destacam-se assuntos gerais que estiveram presentes em mais de um artigo, elencados a seguir:

a) Astronomia: corpos celestes; planetas;

b) Bichos: fundo do mar: vida marinha; bioma: Floresta Amazônica; aracnídeos: aranhas; 
c) Física: força gravitacional; centro de massa; luz; epistemologias das Ciências;

d) Meio Ambiente: preservação ambiental; biomas; parques nacionais;

e) Plantas: espécies endêmicas; florestas brasileiras; parques nacionais;

f) Química: transformações químicas; misturas; fermentação: alimentos;

g) Saúde: doenças; prática de esportes.

No que se refere análises realizadas, a interdisciplinaridade também é um fator a ser considerado para a promoção dos indicadores de AC, a partir de conteúdos de divulgação científica. A figura 2 a seguir apresenta relações instituídas entre as categorias da $\mathrm{CHC}$ Online com diferentes áreas do saber.

FIGURA 2- Eixos de interdisciplinaridade das matérias analisadas Eixos de interdisciplinaridade entre as categorias da CHC online
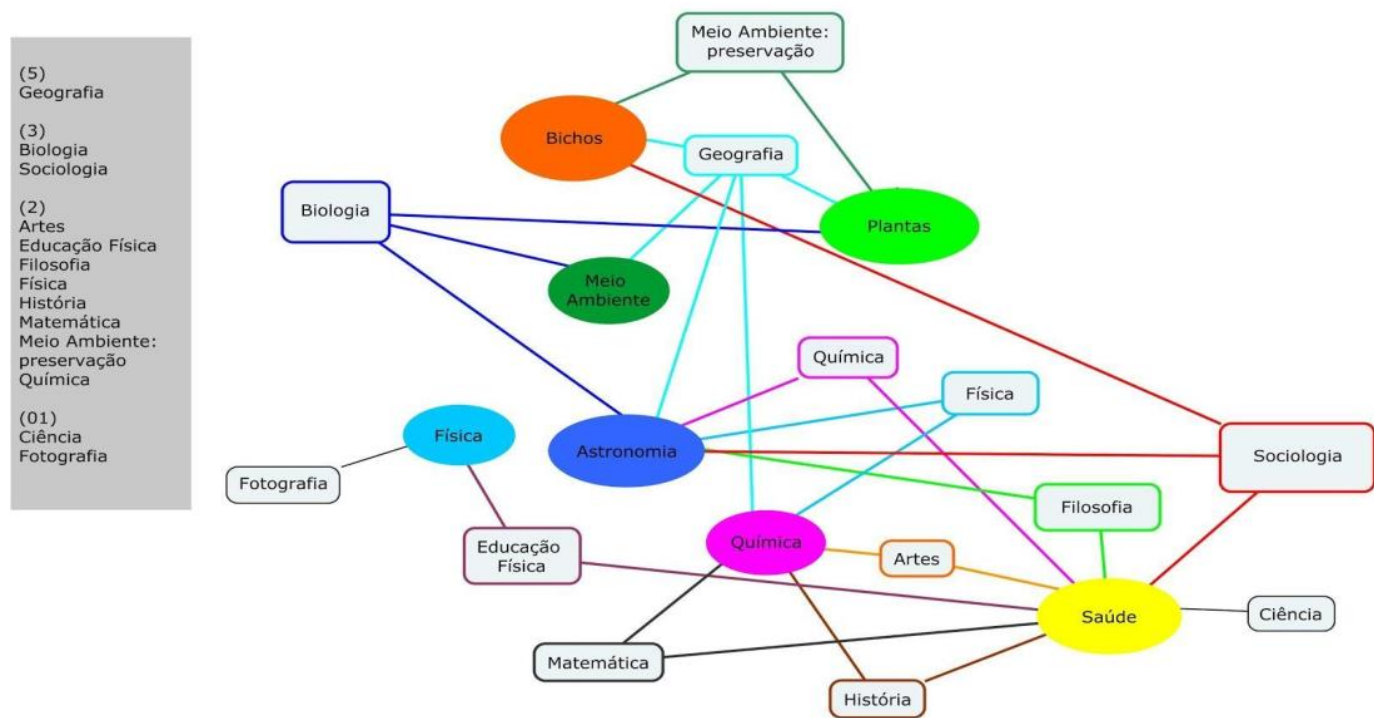

Legenda: À esquerda, apresenta-se o número de vínculos que cada área do conhecimento estabelece com as categorias principais da CHC Online (representadas nos círculos coloridos).

Fonte: Autores, 2018.

A construção do conhecimento científico necessita estar composta por uma série de conteúdos e elementos para que teoria e prática estabeleçam 
interações e significações entre os sujeitos e os contextos sociais. A categoria Saúde fundamenta-se em saberes da área de Ciência, Sociologia, Filosofia, Química, Artes, Educação Física, Matemática e História. A categoria Astronomia está permeada de vínculos com a Biologia, Química, Física, Sociologia e Filosofia. A categoria Química estabelece relações com Matemática, História, artes, Física e Geografia. Plantas relaciona-se com conteúdo da área da Biologia, Geografia e preservação do meio ambiente. A categoria Bichos também estabelece três vínculos: Sociologia, Geografia e preservação do meio ambiente. A categoria Física facilita o dialogar com saberes da área de fotografia e da Educação Física. A categoria Meio Ambiente vincula-se com Biologia e Geografia.

A partir do favorecimento das situações de aprendizagem, pressupõese uma abordagem interdisciplinar de modo a estabelecer relações de complementaridades entre as categorias. Portanto, a interdisciplinaridade mostra-se também curricular, didática e pedagógica (FAZENDA, 2012). Diante do currículo básico para o Ensino de Ciências, estabelecido de modo singular nas diferentes instituições de ensino, há temas fundamentais que compõem os processos de ensino-aprendizagem. Com base nesta demanda, as possibilidades didático-pedagógicas sugeridas a seguir tem relação com os textos analisados na CHC Online.

As sugestões de aplicabilidades didáticas das matérias analisadas estão dispostas a partir temáticas que podem ser exploradas nas diferentes fases e níveis de aprendizagem. A partir das matérias analisadas na $\mathrm{CHC}$ Online, podem-se elencar vários temas que favorecem e estimulam a curiosidade dos estudantes nas aulas de ciências. Os textos são curtos, a linguagem é clara e acessível, ideal não apenas para as crianças, mas também para diferentes perfis de leitores sem limitar os níveis de escolaridade.

A compreensão da vida e da evolução dos seres vivos como os tipos, formas, ambientes em que habitam, mesclam-se nas categorias Bichos, Plantas e Meio Ambiente, que oferecem matérias com distintas abordagens. 
Informações sobre a vida marinha no litoral brasileiro podem ser debatidas a partir de Bonaldo (2017), Bonaldo e Carvalho (2017), Silva (2017). A fauna e a flora da região nordestina estão descritas em São Pedro (2017b). A flora brasileira da região amazônica (ROSSINI, 2016), o pau-brasil (OLIVEIRA, 2017) e as espécies que representam os parques nacionais por meio da singularidade de plantas e animais (SÃO PEDRO, 2016b) também são ideais para estabelecer vínculos entre os estudantes e a diversidade da vida encontrada no território brasileiro.

QUADRO 3 - Possibilidades didático-pedagógicas: relação de temas gerais de Ciências que podem ser desenvolvidos a partir dos textos analisados

\begin{tabular}{|c|c|c|}
\hline $\begin{array}{l}\text { Anos } \\
\text { Iniciais }\end{array}$ & $\begin{array}{l}\text { Conteúdos didático- } \\
\text { pedagógico em Ciências }\end{array}$ & $\begin{array}{l}\text { Categorias da CHC Online: artigos } \\
\text { para mediar a Alfabetização } \\
\text { Científica }\end{array}$ \\
\hline \multirow{3}{*}{ Segundo } & \multirow{3}{*}{$\begin{array}{l}\text { Seres vivos, evolução das } \\
\text { plantas e animais. }\end{array}$} & $\begin{array}{l}\text { Bichos: Bonaldo (2017); Bonaldo; } \\
\text { Carvalho (2017); Silva; Bessa (2017) }\end{array}$ \\
\hline & & $\begin{array}{l}\text { Plantas: Oliveira; Lopes (2017); } \\
\text { Rossini (2016); São Pedro (2016b); } \\
\text { Chagas (2016) }\end{array}$ \\
\hline & & Meio Ambiente: São Pedro (2017b) \\
\hline \multirow{2}{*}{ Terceiro } & $\begin{array}{l}\text { Seres vivos: evolução das } \\
\text { plantas e animais. }\end{array}$ & $\begin{array}{l}\text { Bichos: Silva; Bessa (2017); Costa } \\
\text { (2017a) }\end{array}$ \\
\hline & $\begin{array}{l}\text { Coordenadas geográficas; } \\
\text { corpos celestes; Planetas. }\end{array}$ & $\begin{array}{l}\text { Astronomia: Pinheiro (2016); Reis } \\
\text { Neto (2016) }\end{array}$ \\
\hline \multirow{4}{*}{ Quarto } & $\begin{array}{l}\text { Pontos Cardeais; corpos } \\
\text { celestes Fenômenos cíclicos; } \\
\text { Fases da lua; calendário }\end{array}$ & $\begin{array}{l}\text { Astronomia: Pinheiro (2016); Leal } \\
\text { (2016) }\end{array}$ \\
\hline & Seres vivos: cadeia alimentar & Bichos: Silva; Bessa (2017) \\
\hline & Misturas e transformações & Química: Zíper (2016b); Zíper (2016c); \\
\hline & $\begin{array}{l}\text { Doenças causadas por } \\
\text { mosquitos }\end{array}$ & Saúde: Camar (2016) \\
\hline \multirow{5}{*}{ Quinto } & $\begin{array}{l}\text { Coordenadas geográficas; Luz; } \\
\text { Cores; Atmosfera; Fases da } \\
\text { lua; calendário; }\end{array}$ & $\begin{array}{l}\text { Astronomia: Pinheiro (2016); Reis } \\
\text { Neto (2016); Leal (2016) }\end{array}$ \\
\hline & Artrópodes & Bichos: Costa (2017a); Costa (2017b) \\
\hline & $\begin{array}{l}\text { Preservação ambiental; Fauna } \\
\text { e flora do Brasil; Biomas }\end{array}$ & $\begin{array}{l}\text { Meio ambiente: São Pedro (2016b); } \\
\text { Moreira, et al. (2017); São Pedro } \\
\text { (2017b) }\end{array}$ \\
\hline & Misturas & Química: Zíper (2016b); Zíper (2016c) \\
\hline & $\begin{array}{l}\text { Movimento: esportes, jogos de } \\
\text { equipe }\end{array}$ & Saúde: Pimentel; Fernandes (2016) \\
\hline
\end{tabular}


A importância da água e da luz para a manutenção da vida das plantas e animais ganha destaque na matéria de Chagas (2016), ao descrever a fotossíntese e o consumo de carbono através da dispersão de sementes feitas por mamíferos de grande porte de nossa fauna, como a anta, por exemplo. Este artigo permite que os estudantes construam inferências sobre as relações existentes entre as plantas e os demais seres vivos. O modo de vida dos animais, seus comportamentos e organização em grupos podem ser abordados a partir dos textos de Silva e Bessa (2017) e Costa (2017a). A importância dos ciclos da água para a cobertura vegetal e a conservação do solo são apresentadas por Moreira e colaboradores (2017) num texto que mescla Ciência e Literatura para descrever os caminhos das águas no Cerrado.

Para compreender as características da terra através da observação do céu, das constelações, do sol e da lua, a categoria Astronomia apresenta matérias sobre como os corpos celestes são pontos de referência que ajudam o ser humano a se guiar (PINHEIRO, 2016) e a delimitar territórios (PINHEIRO, 2016). Acerca da variedade de cores no céu, Reis Neto (2016) descreve as influências da luz na atmosfera e ajuda a compreender como a luz do sol incide de acordo com os movimentos de rotação da Terra. Calendários, fenômenos cíclicos e culturais também podem ser compreendidos a partir das perspectivas da Astronomia. O carnaval, uma das festas mais populares Brasil, muda de data a cada ano. A explicação está no céu, é o que conta Leal (2016) ao apresentar como as fases da lua influenciam as festas populares e a formação dos calendários.

A Química pode ser apreendida ao discutir a atuação de microrganismos na produção de alimentos, combustíveis e medicamentos. De modo prático, Zíper, o personagem fictício da CHC Online, procura mostrar às crianças os processos de fermentação através de receitas de iogurte (ZÍPER, 2016b) e de bolo (ZÍPER, 2016c), estimulando o debate sobre os processos de fermentação na alimentação. A Física também pode ser trabalhada nos anos iniciais através de experiências e textos divertidos. A 
força gravitacional possui relação direta com várias atividades cotidianas, como andar numa montanha russa (PIMENTEL, 2016a), pular e praticar esportes (PIMENTEL, 2016b) ou ainda realizar experiências simples para verificar os movimentos da luz (ZÍPER, 2016a).

Debates que envolvem a área da Saúde, essenciais desde o início da formação escolar, podem ser provocados considerando a atuação dos vírus, bactérias e protozoários, tanto no meio ambiente como no organismo dos seres humanos e animais. A transmissão viral por mosquitos (CAMAR, 2016), como o Aedes Aegypt, vetor de doenças da dengue e outros vírus é tema de constantes preocupações em todas as esferas da sociedade. Mas, a busca por saúde e qualidade de vida também são temas essenciais. A prática de exercícios físicos e jogos em equipe são estimulados por Pimentel e Fernandes (2016).

\section{Considerações finais}

A revista $\mathrm{CHC}$ Online é um recurso que promove o acesso ao conhecimento dentro e fora da escola, mediado por professores, familiares ou acessado de modo autônomo pelos estudantes, por isso, pode ser um instigante objeto de estudo. Todos os textos oferecem aplicabilidades teóricas iniciais através da mediação de leitura entre os estudantes. As aplicabilidades práticas também podem ser desenvolvidas, principalmente se inseridas em projetos maiores da escola, com parceria entre disciplinas e professores que fomentem a investigação.

A pesquisa indica favorecimentos da promoção da $\mathrm{AC}$, através de publicações da Revista CHC Online com propostas de temas, cujas matérias são de livre acesso com aplicabilidades práticas e teóricas no meio escolar e incentivam a construção do conhecimento científico a partir de eixos interdisciplinares. Dentro do recorte das 35 matérias analisadas, percebe-se que a CHC Online é um recurso para a divulgação e popularização do conhecimento científico. Tanto em ambientes de ensino quanto em espaços 
não formais. A revista digital oferece textos, jogos, experiências e brincadeiras que podem ser aplicados como facilitadores da $\mathrm{AC}$ na relação entre a ciência e o cotidiano.

As temáticas são familiares ao contexto dos estudantes e passíveis de suscitar elementos facilitadores presentes nos indicadores de AC de Sasseron e Carvalho (2008), Pizarro e Lopes Junior (2015). Os assuntos gerais identificados e analisados a partir das categorias: Astronomia, Bichos, Física, Meio Ambiente, Plantas, Química e Saúde da CHC Online permitiram a possibilidade de explorar uma sequência didática para favorecer a promoção da AC (SASSERON; CARVALHO, 2008), numa perspectiva interdisciplinar.

Priorizou-se a aproximação equilibrada nas diversas áreas da Ciência da Natureza, nos quais os estudantes sejam incentivados à investigação para a compreensão e atuação no seu meio social. São posturas assim, advindas destas abordagens interdisciplinares defendida por Fazenda (2012), que podem permitir melhorias na qualidade do ensino.

As matérias analisadas na CHC Online foram consideradas componentes dos processos de aprendizagem, pois os assuntos e temáticas são acessíveis, sobretudo aos estudantes do anos iniciais do Ensino Fundamental I. Possibilitam, inclusive, o uso de estratégias como a observação, a interpretação e a experimentação indicadores da AC que podem ser considerados na aprendizagem e para o avanço do Ensino de Ciências.

Por fim, essas estratégias viabilizam as buscas pela informação, e assim, possibilitam ao estudante uma posição ativa na construção do conhecimento científico. A literatura mostrou que as buscas em fontes como da CHC Online, além de fornecer informações para a formação de conhecimentos teóricos e práticos, também podem contribuir para o desenvolvimento da autonomia dos estudantes, capacitando-os para desenvolver argumentos e posicionamento crítico. 


\section{Referências}

ALMEIDA, S. A.; GIORDAN, M. A revista Ciência Hoje das crianças no letramento escolar: a retextualização de artigos de divulgação científica. Educação e pesquisa, São Paulo, v. 40, n.4, p. 999-1014, out. /dez. 2014.

BARDIN, L. Análise de Conteúdo. Lisboa: Edições 70, 2009.

CHASSOT, A. Alfabetização científica: questões e desafios para a educação. 8 ed. Ijuí: Unijuí, 2018,

DELIZOICOV, D.; ANGOTTI, J. A. P.; PERNAMBUCO, M. M. Ensino de ciências: fundamentos e métodos. 3 ed. São Paulo: Cortez, 2009.

FAZENDA, I. C. A. Interdisciplinaridade: história, teoria e pesquisa. 18 ed. Campinas: Papirus, 2012.

FREIRE, P. Pedagogia da autonomia: saberes necessários à prática educativa. São Paulo: Paz e terra, 1996.

FRAGA, F. B. F. F.; ROSA, R. T. D. Microbiologia na revista Ciência Hoje das Crianças: análise de textos de divulgação científica. Ciência e Educação,

Bauru, vol.21 n.1, jan./mar. 2015. Disponível em:

$<$ http://www.scielo.br/scielo.php?script $=$ sci arttext\&pid=S1516-

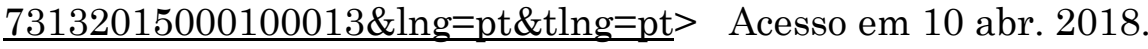

GIL, A. C. Métodos e técnicas de pesquisa social. 6. Ed. São Paulo: Atlas, 2008.

HOLBROOK, J.; RANNIKMAE, M. The meaning of scientific literacy. International Journal of Environmental \& Science Education, vol. 4, no. 3, p. 275288, 2009.

INSTITUTO Ciência Hoje. História. [2016]. Site oficial. Disponível em: $<$ http://cienciahoje.org.br/instituto/historia/>. Acesso em: 19 jul. 2018.

MASSARANI, L. La divulgación científica para niños. Quark: periodismo científico en un mundo diverso, n. 34, out./dez. 2007. Disponível em:

$<$ http://www.prbb.org/quark/17/017040.htm>. Acesso em: 19 jul. 2018.

MORAN, J. M.; Ensino e aprendizagem inovadores com tecnologias audiovisuais e telemáticas. In: MASETTO, M. T; BEHRENS, M. A. Novas tecnologias e mediação pedagógica. 15 ed. Campinas: Papirus, 2009. p.11-65.

MOZENA, E. R.; OSTERMANN, F. Uma revisão bibliográfica sobre a interdisciplinaridade no Ensino de Ciências da Natureza. Ensaio: Pesquisa em Educação em Ciências (Online), v. 16, p. 185-206, 2014. Disponível em: $<$ http://www.scielo.br/scielo.php?script=sci_arttext\&pid=S1983-

21172014000200185\&lng=pt\&tlng=pt>. Acesso em 10 jun. 2018. 
NORRIS, S. P.; PHILLIPS, L. M. How literacy in its fundamental sense is central to scientific literacy. Science Education, v. 87, n. 2, p. 224-240, 2003.

PIZARRO, M.V.; LOPES JUNIOR, J. Indicadores da alfabetização científica: uma revisão bibliográfica sobre as diferentes habilidades que podem ser promovidas no ensino de ciências nos anos iniciais. Investigações em Ensino de Ciências, Porto Alegre, v. 20, n. 1, p. 208-238, 2015.

ROCHA, M.; MASSARANI, L. Divulgação científica na internet: um estudo de caso de comentários feitos por leitores em textos da Ciência Hoje das Crianças Online. Alexandria: Revista de Educação em Ciência e Tecnologia, v.9, n.1, p.207-233, maio 2016.

SOBRE a CHC. Ciência Hoje das Crianças: site oficial. Rio de Janeiro, [2016]. Disponível em: <http://chc.org.br/sobre-a-chc/>. Acesso em: 28 abr., 2018.

SASSERON, L. H.; CARVALHO, A. M. P. Almejando a alfabetização científica no ensino fundamental: a proposição e a procura de indicadores do processo. Investigações em Ensino de Ciências, Porto Alegre, v. 13, n. 3, p. 333-352, 2008.

VALENTE, J.A. A sala de aula invertida e a possibilidade do ensino personalizado: uma experiência com a graduação em midialogia. In: BACICH, L.; MORAN, J. (orgs) Metodologias Ativas para uma educação inovadora: uma Abordagem teóricoprática. Porto Alegre: Penso, 2017. p. 26-44

TENREIRO-VIEIRA, C.; VIEIRA, R. M. Educação em ciências e em matemática numa perspectiva de literacia: desenvolvimento de materiais didáticos com orientação CTS/ pensamento crítico (PC). In: SANTOS, W. L. P. dos; AULER, D. (Orgs.). CTS e educação científica: desafios, tendências e resultados de pesquisas. Brasília: Editora Universidade de Brasília, 2011.

\section{Referências dos textos analisados}

BONALDO, R. Pequenos notáveis: conheça os peixes criptogenéticos! Ciência Hoje das Crianças Online, Instituto Ciência Hoje, 03 out. 2017. Disponível em: <http://chc.org.br/pequenos-notaveis/>. Acesso em: 22 abr. 2018.

BONALDO, R; CARVALHO, A. E. Oito braços que pensam? Conheça os polvos, animais incríveis! Ciência Hoje das Crianças Online, Instituto Ciência Hoje, 07 ago. 2017. Disponível em: < http://chc.org.br/oito-bracos-que-pensam/>. Acesso em: 22 abr. 2018.

CAMAR, T. N. L. Por que alguns mosquitos são transmissores de doenças? Ciência Hoje das Crianças Online, Instituto Ciência Hoje, 30 nov. 2016. Disponível em: $<$ http://chc.org.br/acervo/por-que-alguns-mosquitos-sao-transmissores-dedoencas/>. Acesso em: 29 abr. 2018.

CHAGAS, C. A anta, o carbono e o clima. Você pensa que uma coisa não tem nada a ver com a outra? Ciência Hoje das Crianças Online, Instituto Ciência Hoje, 06 jan. 
2016. Disponível em: <http://chc.org.br/a-anta-o-carbono-o-clima/>. Acesso em: 24 abr. 2018.

COSTA, H. C. Aranhas com nome de comida? Ciência Hoje das Crianças Online, Instituto Ciência Hoje, 11 ago. 2017a. Disponível em: <http://chc.org.br/aranhascom-nome-de-comida/>. Acesso em: 22 abr. 2018.

COSTA, H. C. Descoberta por acaso: uma nova espécie da Amazônia. Ciência Hoje das Crianças Online, Instituto Ciência Hoje, 29 ago. 2017b. Disponível em: <http://chc.org.br/descoberta-por-acaso/>. Acesso em: 22 abr. 2018.

LEAL, T. Folia que passeia pelo calendário: a cada ano o carnaval é comemorado em uma data diferente. Ciência Hoje das Crianças Online, Instituto Ciência Hoje, 08 fev. 2016. Disponível em: <http://chc.org.br/folia-que-passeia-pelo-calendario/>. Acesso em: 23 abr. 2018.

MOREIRA, S.; SOUZA, F.; POTT, V.; POTT, A. Vereda: caminho das águas do cerrado. Ciência Hoje das Crianças Online, Instituto Ciência Hoje, 03 fev. 2017. Disponível em: <http://chc.org.br/vereda/>. Acesso em: 22 abr. 2018.

OLIVEIRA, W. C. de; LOPES, A. V. Brasileirinha. Conheça o Pau-brasil árvore símbolo do país. Ciência Hoje das Crianças Online, Instituto Ciência Hoje, 24 abr. 2017. Disponível em: <http://chc.org.br/brasileirinha/>. Acesso em: 22 abr. 2018.

PIMENTEL, B. Borboletas no estômago. Ciência Hoje das Crianças Online, Instituto Ciência Hoje, 14 set. 2016[a]. Disponível em: <http://chc.org.br/borboletasna-barriga/>. Acesso em: 22 abr. 2018.

PIMENTEL, B. Ciência nos esportes. Ciência Hoje das Crianças Online, Instituto Ciência Hoje, 24 ago. 2016[b]. Disponível em: <http://chc.org.br/ciencia-nosesportes/>. Acesso em: 28 abr. 2018.

PIMENTEL, R., FERNANDES, T. Vamos mexer o corpo. Ciência Hoje das Crianças Online, Instituto Ciência Hoje, 10 nov. 2016. Disponível em:

<http://chc.org.br/vamos-mexer-o-corpo/>. Acesso em: 29 abr. 2018.

PINHEIRO, I. Olhar o céu para medir a terra: entenda como as estrelas e outros corpos celestes ajudaram a delimitar o território brasileiro. Ciência Hoje das Crianças Online, Instituto Ciência Hoje, 02 mar. 2016. Disponível em: < http://chc.org.br/olhar-o-ceu-para-medir-a-terra/>. Acesso em: 23 abr. 2018.

REIS NETO, E. O céu também é azul em outros planetas? Ciência Hoje das Crianças Online, Instituto Ciência Hoje, 11 jan. 2016. Disponível em: < http://chc.org.br/o-ceu-tambem-e-azul-em-outros-planetas/>. Acesso em: 23 abr. 2018 .

ROSSINI, J. P. Desconhecidas e inexploradas: biólogos visitaram florestas montanhosas da região amazônica para explorar sua flora. Ciência Hoje das Crianças Online, Instituto Ciência Hoje, 23 maio 2016. Disponível em: <http://chc.org.br/desconhecidas-e-inexploradas/>. Acesso em: 24 abr. 2018. 
SÃO PEDRO, V. Jardim do Brasil. Ciência Hoje das Crianças Online, Instituto Ciência Hoje, 08 jun. 2016[a]. Disponível em: <http://chc.org.br/jardim-do-brasil/>. Acesso em: 23 abr. 2018.

SÃO PEDRO, V. Oásis na caatinga cearense. Brejos de Altitude: áreas especiais no sertão nordestino. Ciência Hoje das Crianças Online, Instituto Ciência Hoje, 13 jan. 2017[b]. Disponível em: <http://chc.org.br/oasis-na-caatinga-cearense/>. Acesso em: 22 abr. 2018.

SÃO PEDRO, V. Parques e seus mascotes. Ciência Hoje das Crianças Online, Instituto Ciência Hoje, 29 jan. 2016[b]. Disponível em: <http://chc.org.br/parques-eseus-mascotes/>. Acesso em: 24 abr. 2018.

SILVA, F.; BESSA, E. Um mergulho com os peixes. Ciência Hoje das Crianças Online, Instituto Ciência Hoje, 17 jul. 2017. Disponível em: <http://chc.org.br/ummergulho-com-os-peixes/>. Acesso em: 22 abr. 2018.

SILVA, J. T. Química que colore o céu. Ciência Hoje das Crianças Online, Instituto Ciência Hoje, 26 set. 2016. Disponível em: < http://chc.org.br/quimica-que-colore-oceu/>. Acesso em: 29 abr. 2018.

ZÍPER[personagem fictício]. Desenho de luz. Ciência Hoje das Crianças Online, Instituto Ciência Hoje, 29 ago. 2016[a]. Disponível em: <http://chc.org.br/desenhode-luz//>. Acesso em: 22 abr. 2018.

ZÍPER [personagem fictício]. Iogurte sabor ciência. Ciência Hoje das Crianças Online, Instituto Ciência Hoje, 26 set. 2016[b]. Disponível em:

<http://chc.org.br/iogurte-sabor-ciencia>. Acesso em: 29 abr. 2018.

ZÍPER [personagem fictício]. Por que o bolo cresce? Ciência Hoje das Crianças Online, Instituto Ciência Hoje, 12 abr. 2016[c]. Disponível em:

<http://chc.org.br/por-que-o-bolo-cresce/>. Acesso em: 29 abr. 2018.

Recebido em novembro de 2018. Aprovado em maio de 2019. 